\title{
Evolution of Leadership and Organizational Culture Research on Innovation Field: 12 Years of Analysis
}

\author{
Mohamed Zennouche, Jian Zhang \\ Dongling School of Economics \& Management, University of Science and Technology, Beijing, China \\ Email: m.zennouche@hotmail.com, zhangj67@manage.ustb.edu.cn
}

Received 10 March 2014; revised 13 April 2014; accepted 21 April 2014

Copyright (C) 2014 by authors and Scientific Research Publishing Inc.

This work is licensed under the Creative Commons Attribution International License (CC BY). http://creativecommons.org/licenses/by/4.0/

c) (i) Open Access

\begin{abstract}
Many scholars assume that both leadership and organization culture play important roles in fostering innovation. The paper analyzes 12 years of leadership and organizational culture on innovation field research in the top eight management journals. The purpose of this paper is to summarize the relation studies between the two factors to investigate connections between organizational culture and leadership. Through a content analysis, it studies the relationship between leadership and organizational culture and its related studies to innovation on each journal. Moreover, the finding showed evolution of research on the 12 years of analysis. At the end, the paper is concluded by discussing several issues in leadership and organizational culture that need further investigation.
\end{abstract}

\section{Keywords}

\section{Leadership; Organizational Culture; Innovation}

\section{Introduction}

Innovation is about a process of developing and implementing a new idea [1]. [1] they go on to write that innovation refers to the process of bringing in any new problem solving idea and implementation of new ideas, processes, products, or service. Innovation is critical for organizational long-term prosperity, particularly in dynamic markets [2]. [3] defines innovation as "change" and includes the creation and commercialization of new knowledge in terms of a firm's. As these definitions make clear, innovation is not limited to technological change or new products even though it is frequently described in this way.

Leadership and culture are linked in developing and implementing, namely process of change [4], he states, 
only through leadership can one truly develop and nurture culture that is adaptive to change. [5] suggested that leadership style and organizational culture are linked; it was proposed that organizational culture mediates the association between leadership style and performance. Leadership style is not directly linked to performance but is merely indirectly associated. While competitive and innovative cultures which are sensitive to external conditions have a strong and positive impact on organizational performance. The generation of an organizational culture, which is externally oriented, is significantly influenced by the extent to which a leader is supportive of followers and includes followers in decision-making processes.

Others who have studied relationship between organizational culture and innovation include [6]-[8] also suggest the presence of a relationship. [4] record that only a few empirical studies on the impact of organizational culture on organizational innovation exist. The culture of the organization should be developed to support continuous improvement, improve employees' style of performing their job and thus develop quality awareness. Organizational culture has influenced employee work behavior as a result of the acceptable behaviors and attitudes to various jobs in the organization. Organizational culture is a major determinant of an employee's efficiency and effectiveness in carrying out their jobs. That is, organizational culture and leadership are two major determinants of how employees perform or behave in his job to achieve organizational success.

The aim of this research to investigate the relation between leadership and organizational culture as two fostering factors of innovation, based on 12 last years of publications on the field of innovation with answering the following question: what are the existing trends in innovation research field with relation to leadership and organizational culture during 12 years period, from 2000 to 2102?

\section{Search Methodology}

\subsection{Sample Selection}

In so doing our intention was to provide an initial "picture" of the current state-of-the-relation between leadership and organizational culture on the innovation field research, in these regards and to present an overview of current themes based upon this content analysis. The scope of this review paper, to undertake an exhaustive, multi-decade content analysis of all innovation studies published over the most recent 12 years (2000-2012) in the top rated scientific journals in management. Academy of Management Journal (AMJ), Administrative Science Quarterly (ASQ), Journal of Applied Psychology (JAP), Journal of Organizational Behavior (JOB) Organization Science (OS), Organizational Behavior and Human Decision Processes (OBHDP), Journal of Creative Behavior (JCB), Creativity Research Journal (CRJ). The evidence of this comes from Social Science Citation Index (SSCI).

\subsection{Data Collecting}

Our content analysis was shown several steps: firstly, we searched for journal articles using the online database web of (SSCI). We used the creativity, creative, innovation, innovative, innovativeness keywords in our search (the reason for using the keyword creativity is because that occasionally used interchangeably with innovation in the literature). Secondly, we read each abstract in order to identify those articles 1) were published between the period 2000-2012, 2) were published in the above eight journals and 3) had relationship to the leadership or organization. In order to decide in which factor(leadership or organizational culture) was submitted; we read each abstract carefully; for example if the abstract talked about the leadership general the article would be classified into leadership factor, if an abstract indicated that the study about organizational culture it would be classified into organizational culture factor. At end of our analysis we identified 76 articles. In the next step, we listed the articles associated with leadership and organizational culture based on the following criteria: if the abstract talked about relationship between leadership and organizational culture, in order to accurately the trend of the past 12 years in the field of innovation and its related influencing factors (leadership, organizational culture) and make the result more clearly understood.

\section{Result}

\subsection{Relationship between Leadership and Organizational Culture on Innovation Field 2000-2012}

The results tell us about how leadership and organizational culture are happening on the innovation. These re- 
sults of 12 years of analysis suggest that the surveyed factors rated their influence studies differed from each journal to others. The Figure 1 is a line chart that illustrates the leadership and organizational culture on each journal. The $\mathrm{Y}$ axis is measured by the percentage of publications of leadership and organizational culture on each journal and increases by increments of 0.05 from 0 to 0.3 . The $\mathrm{X}$ axis is measured by journals used for this study. From Figure 1, it can clearly be seen that there has been a large increase in the number of publications of leadership on the journals JCB, CRJ, JAP, JOB, AMJ compared to the publications of organizational culture on the same journals. While the graph shows a slight growth for the leaderships publications on OBHDP, ASQ, OS, compared to the organizational culture publication on the same mentioned journals.

\subsection{The Related Studies between Leadership and Organizational Culture on Innovation in Each Journal}

The Figure 2 illustrate the related studies of leadership and organizational culture in each journal. The green line represents related studies of leadership and organizational culture, while the blue and the red colors represent leadership and organizational culture respectively. As you can see, there is a horizontal green line with small circles which mentioned the related studies. Moreover; we can see an identical circle on the line of organizational culture studies, while there are other non-identical where it can be shot down vertically converging with both the circles of leadership and organizational culture studies. In addition the journals which have related studies of leadership and organizational culture are OBHDP, JAP, and JOB with frequency 0.5, 0.33, 0.2, respectively with total of 1.03 . This result could be explained by the attention of researchers in the two factors leadership and organizational culture on the field of innovation especially on the above three journals.

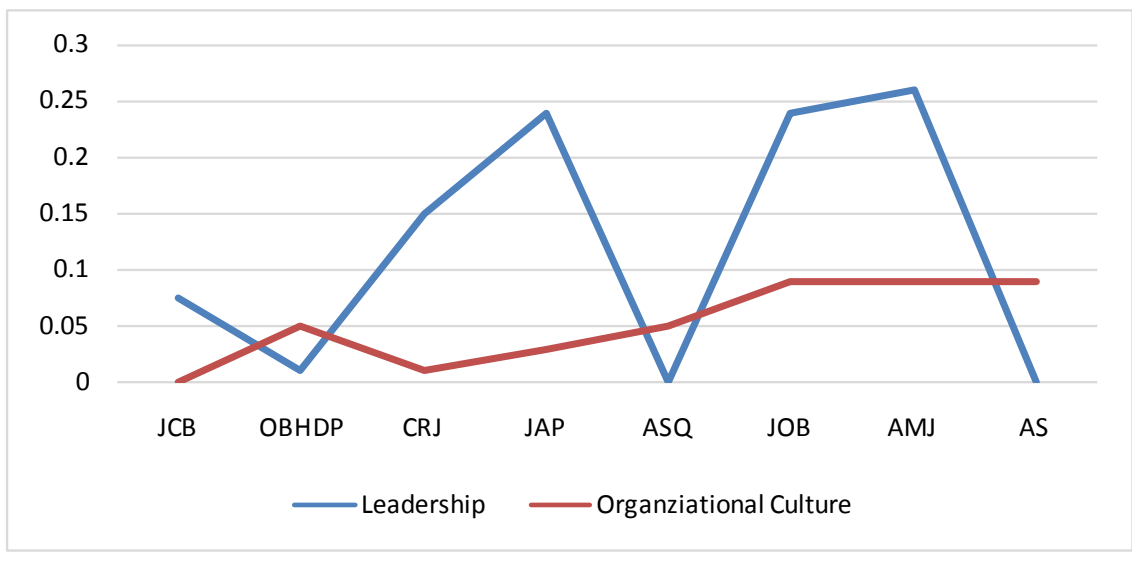

Figure 1. Studies percentage frequency of leadership and organizational culture on innovation field.

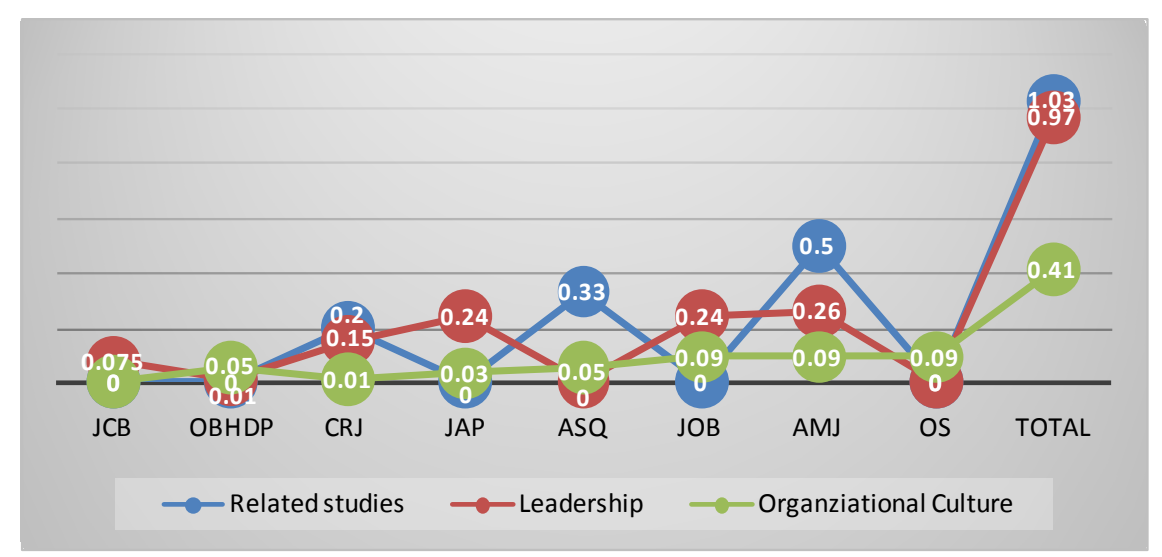

Figure 2. Related studies between leadership and organizational culture on innovation field in each journal. 
The number of related studies between 2000-2012 are mentioned on the Figure 3, leadership and organizational culture related studies have risen considerably over the year 2010, before the year 2010 there were nearly 0.00 related studies, This number climbed to approximately 0.66 per studies in 2010, then decrease dramatically to 0.00 in 2011. Since 2011 there has been a steady increase, with around 0.25 related studies in 2012. The corresponding Figure 3 of related studies between the two factors with years also shows a crease augmentation of studies which mentioned with linear line.

\section{Discussion and Recommendation}

The main purpose of this review was to summarize and investigates the relationship of leadership and organizational culture factors related to innovation outcomes. In our analysis of the 12 years of publication in top management journals, we identified the main research directions about leadership and organizational culture on the innovation field. Through, content analyzing the past 12 years of researches in AMJ, ASQ, JAP, JOB, OS, OBHDP, JCB and CRJ, we also got the relationship leadership and organizational culture and found the growth of innovation studies over journals. Our results reflected the evolution of leadership and organizational culture factors on innovation field as a whole and also raised some questions about future directions.

Certainly, our finding based on 76 studies published in this area represented the relationship leadership and organizational. The results of the study illustrated that there has been a significant increase in JCB, CRJ, JAP, JOB, AMJ compared to the publications of organizational culture on the same journals. While there was a slight growth for the leaderships publications on OBHDP, ASQ, OS, compared to the organizational culture publication on the same mentioned journals. Furthermore, the research of leadership and organizational culture in a number of articles published between (2000 and 2012) are increased in the year 2010 where number of publications climbed to 0.66 studies in a while before 2010 were nearly 0.00 related studies, then decrease in 2011. Since 2011 there has been a steady increase, with around 0.25 related studies in 2012 see Figure 3.

Based on what we found, that organizational culture is crucial to enable innovation and further, that leadership and organizational culture work in conjunction with each other. Organization culture is intimately intertwined and that both are needed in order to successfully innovation. Prior research has left unanswered the question about whether leadership or organization culture has a greater impact on innovation [9]. Some researchers found organizational culture is a major factor influencing innovation [4] [9]. While some others scholars have found a connection relationship between leadership and innovation [10]. Moreover, the study results suggest to provide additional insight into just how leadership and culture work together and for what purpose, when it comes to innovation.

Clearly, there is a need for further study to investigate exactly how leaders actually promote innovative activities through organizational culture. While cross sectional research is useful, we need to add the more dynamic perspective that real-time case studies could provide. Because our study focused on 12 years period of search. In addition, our finding suggest to search more on this important area especially in the journal of on OBHDP, ASQ, OS for leadership research and JCB, CRJ, JAP, JOB, AMJ for organizational culture research.

There are also limitations in this study connected with its general framework, as well as a consequence of our having investigated only a few dimensions of innovation, leadership, and organization culture. Thus, we can provide only an incomplete picture of the relationship leadership and organizational culture in affecting

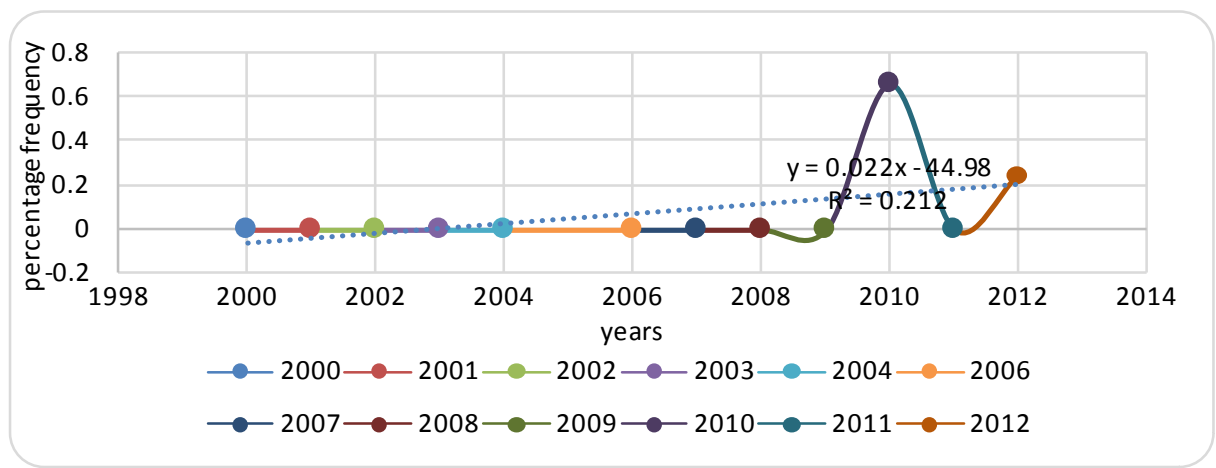

Figure 3. Evolution of leadership and organizational culture research from 2000 to 2012. 
innovation. This calls for more research that looks at additional aspects of these variables. But, by taking a more fine grained approach to investigating the relationships among leadership, organization culture and innovation, our study has made clear the need for future research to include multiple dimensions of each of these variables in their investigations. As well, it makes clear the importance of examining each leadership sub factors separately in order to understand each sub factors effect on innovation, and each sub factors interactions with other factors, including organization culture sub factors.

\section{Conclusion}

The concepts of leadership as well as the importance of organizational culture have received much attention both in research and in practice over the last decade. We have seen that the research approach has analytically reviewed leadership and organizational culture as key factors of innovation. Organizations that want to achieve their goals with high performance should enhance the conjunction of leadership and organizational culture. The link between these two areas seems clear and has also been commented on by many authors. However, too little systematic research has been done in order to gain the necessary insight in this link. In this paper, the relation among organizational culture, leadership and innovation was explored between 2000 and 2102. Several ways of looking at the link between leadership and culture were described, such as the different roles leaders can play in creating, managing or changing organizational culture but also the way the content of organizational culture can be related to the different types of leadership to achieve innovation. It was shown through an illustrative study that leadership has a stronger relationship with a more innovative and supportive organizational culture. The paper was concluded by describing several possible areas of research in the field of organizational culture and leadership as key factors of innovation.

\section{Acknowledgements}

We especially thank the National Science Foundation of China (70771009, 71071017) and the Fundamental Research Funds for the Central Universities (FRF-BR-09-019) for supporting this research.

\section{References}

[1] Van de Ven, A.H. and Poole, M.S. (1989) Methods for Studying Innovation Processes. In: Van de Ven, A.H., Angle, H.L. and Poole, M.S., Eds., Research on the Management of Innovation, Harper \& Row, New York, 31-54.

[2] Wolfe, R.A. (1994) Organizational Innovation: Review, Critique and Suggested Research Directions. Journal of Management Studies, 31, 405-431. http://dx.doi.org/10.1111/j.1467-6486.1994.tb00624.x

[3] Porter, M.E. (1980) Competitive Strategy: Techniques for Analyzing Industries and Competitors. The Free Press, New York.

[4] Kotter, J.P. and Heskett, J.L. (1992) Corporate Culture and Performance. The Free Press, New York.

[5] Emmanuel, O. and Lloyd, C.H. (2000) Leadership Style, Organizational Culture and Performance: Empirical Evidence from UK Companies. International Journal of Human Resource Management, 11, 766-788. http://dx.doi.org/10.1080/09585190050075114

[6] Abbey, A. and Dickson, J. (1983) R \& D Work Culture and Innovation in Semiconductors. Academy of Management Journal, 266, 362-368.http://dx.doi.org/10.2307/255984

[7] Convoy, E. and Mac Makin, J. (1997) Developing a Culture for Innovation: What Is the Role of the HR System?

[8] Oldham, G.R. and Cummings, A. (1996) Employee Creativity: Personal and Contextual Factors at Work. Academy of Management Journal, 39, 607-634. http://dx.doi.org/10.2307/256657

[9] Jung, D.I., Chow, C. and Wu, A. (2003) The Role of Transformational Leadership in Enhancing Organizational Innovation: Hypotheses and Some Preliminary Findings. The Leadership Quarterly, 14, 525-544. http://dx.doi.org/10.1016/S1048-9843(03)00050-X

[10] Tushman, M. and Nadler, D. (1986) Organizing for Innovation. California Management Review, 28, 74-92. http://dx.doi.org/10.2307/41165203 